\title{
Recomendaciones para una presentación oral
}

\author{
Anna M. Pulpón Segura ${ }^{a}$, M. Teresa Icart Iserna ${ }^{a}$ María Nolla Domenjób, \\ Carmen Caja López y Montserrat Solà Pola ${ }^{\mathrm{b}}$
}

"Escola d'Infermeria de la Universitat de Barcelona. 'Fundació Doctor Robert. 'Institut d'Estudis de la Salut. Barcelona.

Los profesionales de la salud deben ser competentes en el desarrollo de su disciplina, pero además deberán ser hábiles en el manejo de las herramientas destinadas a la comunicación, cuyo uso será necesario en algún momento de su carrera profesional.

El presente artículo describe algunos de los elementos que intervienen antes, durante y después de la comunicación oral y que pueden ser útiles para mejorar las habilidades personales para realizar una exposición oral.

Enfrentarse a una audiencia puede producir cierta angustia y nerviosismo que es necesario controlar, la preparación de la intervención oral y de los medios audiovisuales, asi como el uso de los elementos paralingüísticos y el lenguaje del cuerpo, pueden disminuir la tensión nerviosa y aumentar el rendimiento de la exposición oral, condiciones indispensables para una exposición efectiva.

Palabras clave:

Comunicación cientifica. Paralingüísticos. Medios audiovisuales.
Oral presentations and classroom observation. Development of a specific recording tool to assess learning

Health professionals should be competent in exercising their profession and should also possess good communication skills, which will be required at some point in their careers.

The present article describes some of the elements that are involved before, during and after oral presentations and which may be useful for improving the delivery of presentations.

Speakers need to know how to control the anxiety that can be produced by facing an audience; preparation of the presentation and the audiovisual aids as well as the use of paralinguistic elements and body language can reduce nervous tension and improve delivery. These conditions are indispensable for an effective presentation.

Key words:

Scientific Communicatión. Paralinguistic. Audiovisual tools.

\section{INTRODUCCIÓN}

El siglo xx se ha caracterizado por la explosión de los sistemas de comunicación y en el nuevo milenio se ha acuñado la expresión de la sociedad de las tecnologías de la información y la comunicación (TIC), donde de manera constante se recibe una gran cantidad de información: escrita, oral, audiovisual, electrónica, en muchas ocasiones difícil de procesar.

Correspondencia: A.M. Pulpón

Escola Universitària d'Infermeria

Feixa Llarga, s/n. 08907 L'Hospitalet de Llobregat. Barcelona.

Correo electrónico: apulpon@bell.ub.es
Por otro lado, el mundo de la imagen ha revolucionado nuestro entorno. El diseño gráfico se ha incorporado tanto a los documentos escritos como a la comunicación oral; las audiencias no quieren escuchar solamente contenidos de calidad, sino que además se exige que estos contenidos se presenten de forma atractiva.

En esa línea, Morgan ${ }^{1}$ expone que, en general, los profesionales no quieren pasar largas horas sentados escuchando comunicaciones, aunque afirma que a la vez no pueden vivir sin ellas. Se admite que una presentación buena y cuidada tiene el poder de motivar, convencer, crear cambios y generar un intercambio de ideas. 
En general, la mayoría de individuos tienen que enfrentarse, en un momento u otro de su carrera profesional, a una situación comunicativa. Cada día nuestro entorno laboral nos exige mayores y mejores habilidades para desarrollar esta actividad; la comunicación oral se ha convertido, pues, en un elemento esencial en la mayoría de las profesiones ${ }^{2}$.

En el contexto sanitario, enfermeras, médicos, trabajadores sociales, etc. han de ser competentes en esta actividad; no sólo han de comunicarse de forma eficaz y efectiva durante el encuentro clínico con el paciente, sino que además han de cultivar el arte de comunicar en otros ámbitos profesionales, como sesiones clínicas, congresos, reuniones científicas y mesas redondas, entre otros. En estas circunstancias, además de exponer resultados sobre algún trabajo científico o experiencias profesionales, deberán enfrentarse cara a cara con una numerosa audiencia.

El objetivo de este artículo es presentar algunos de los elementos que intervienen en la comunicación oral y que pueden ser útiles para mejorar las habilidades personales en el transcurso de una exposición oral.

\section{ANTES DE LA EXPOSICIÓN ORAL}

A menudo, tener que hablar ante una audiencia produce un cierto miedo escénico: el nerviosismo que sienten la mayoría de los oradores debe interpretarse como un estado natural previo a la presentación oral. Pero este miedo escénico se puede llegar a controlar y, además, es deseable que así sea, aunque ello no significa que podamos eliminarlo por completo ${ }^{3}$.

Cada persona reacciona de manera distinta ante una situación en la que tiene que hablar en público, pero hay algunos elementos que deben tenerse en cuenta: una de las manifestaciones más comunes del miedo escénico es la angustia que puede presentar diferentes grados de afectación:

- Nivel somático: taquicardia, disnea suspirosa, sudación, dolor de cabeza y de estómago, enrojecimiento facial, etc.

TABLA 1. Recomendaciones para el control de la tensión nerviosa

Al inicio llevar a cabo algunas respiraciones profundas, abdominales o diafragmáticas

No permanecer inmóvil

Concentrase en la materia que se expone

Mirar de manera general a la audiencia

Utilizar audiovisuales
- Nivel cognitivo: pensamientos negativos relacionados con la comunicación que se ha de realizar y con una anticipación de consecuencias desfavorables.

- Nivel conductual: alteraciones en la voz (temblor, tartamudeo y equivocaciones frecuentes), deseo de evitar el momento de realizar la presentación, uso exagerado de adaptadores (tocarse el cabello, dar vueltas al anillo, ajustarse el nudo de la corbata, quitar y ponerse las gafas repetidamente, etc.).

Un aspecto que puede ayudar a controlar la angustia de tener que hablar en público es conocer a fondo el tema sobre el que se va a hablar y prepararlo concienzudamente. La elaboración de un guión puede ayudar al orador a ganar confianza en sí mismo.

Para la preparación de la intervención oral, es fundamental responder a las siguientes preguntas, que corresponden a las etapas de la elaboración de un discurso:

- ¿Cuál es el objetivo de mi presentación? El objetivo general puede ser entretener, informar o persuadir, mientras que el específico expresa cuál es la respuesta que el orador espera del público.

- ¿A quién va dirigida la presentación? El análisis de la audiencia que escuchará, y el conocimiento de sus intereses, ayudará a establecer un terreno común para conseguir una comunicación más efectiva.

- ¿Cómo se ha de estructurar la información que se quiere presentar? Un discurso debe contener, además del título, una introducción que capte la atención del público y sirva de guía hacia el siguiente apartado: la parte central, el cuerpo del discurso, en el que se desarrollan los contenidos principales del tema y, finalmente, se exponen las conclusiones que resumirán el contenido del mensaje.

Otro punto importante es ensayar la comunicación, dedicando una atención especial al inicio y al final: estos dos momentos son cruciales en cualquier exposición que se realice. Los primeros minutos sirven para captar el interés y la atención de la audiencia y coinciden precisamente con el momento de máximo nerviosismo del orador; en cuanto al final, debe contener de manera clara y concisa las conclusiones del trabajo presentado.

Además de todo lo expuesto, es aconsejable que el día de la comunicación se tengan en cuenta otras recomendaciones para controlar la tensión nerviosa (tabla 1).

\section{DURANTE LA EXPOSICIÓN ORAL}

Además del contenido del propio discurso, intervienen otros elementos que influyen de manera determinante en el ánimo de los oyentes: 
- Elementos paralinguísticos: la voz.

- Elementos no verbales: la expresión facial, los gestos, la postura, los movimientos, etc.

\section{La voz}

La imagen auditiva tiene un gran impacto para la audiencia, y por tanto el orador ha de saber que su voz puede ser un gran aliado o el peor de sus enemigos. El tono, el volumen, la velocidad y la pronunciación son cuatro de las características de la voz que es necesario aprender a utilizar, de forma correcta y consciente, durante una presentación oral; con una combinación correcta de estos elementos, evitaremos la monotonía, el aburrimiento o el cansancio entre los que nos escuchan. Así pues, es fundamental recordar que uno de los recursos más poderosos que existen para captar la atención de la audiencia es el hacer un uso correcto de la voz (tabla 2).

\section{La expresión facial}

El rostro y la mirada son los componentes más importantes del lenguaje no verbal. La mirada contiene una fuerza especial que puede condicionar a quien se siente observado y producirle, o no, reacciones asertivas. Por este motivo durante una exposición, la mayoría de las personas de un auditorio deben tener la sensación de que, en algún momento, el que habla se dirige especialmente a ellos.

\section{El lenguaje del cuerpo}

La mayoría de expresiones corporales se adquieren de forma inconsciente, pero emiten un mensaje no verbal: es necesario aprender a incorporar en nuestro discurso aquellos elementos gestuales que enriquecen y favorecen la comunicación con la audiencia. La postura del cuerpo debe ser relajada, evitando gestos y movimientos repetitivos o exagerados. Debe recordarse que los ademanes sirven para apoyar nuestra comunicación verbal y pueden completar, enfatizar o contradecir lo que se expresa oralmente; por tanto, se

TABLA 2. Procedimientos para aumentar el rendimiento de la voz

\footnotetext{
Variar la entonación y el volumen de la voz: añade color e interés a lo que se va a decir

Enfatizar los puntos clave mediante la velocidad y la dicción

Utilizar pausas vacias: silencios entre el final y el inicio de una frase
}

debe evitar tener objetos en las manos o esconderlas ya que ello dificulta la expresión corporal adecuada que refuerza o acompaña el discurso ${ }^{4}$.

\section{Los medios audiovisuales}

Como se ha indicado al inicio de este artículo, nos encontramos en la sociedad de las TIC donde las imágenes visuales tienen un gran protagonismo. Algunos estudios realizados en la Warton University de Pennsylvania demuestran que se recuerda un $10 \%$ de lo que se lee, un $20 \%$ de lo que se escucha y un $50 \%$ de la información que se recibe por vía visual. Por tanto, es casi obligatorio utilizar medios audiovisuales en cualquier exposición oral que se realice ${ }^{5}$. Los más utilizados por conferenciantes, oradores o docentes son la pizarra, el rotafolios, el vídeo, las transparencias, las diapositivas y las presentaciones electrónicas ${ }^{6}$.

- La pizarra: es uno de los medios más tradicionales y hasta hace poco ha sido el recurso imprescindible para cualquier docente. Todavia en la actualidad, conserva gran parte de su valor, aunque ha ido sustituyéndose paulatinamente por la pizarra blanca y el rotafolios oflip chart.

- El flip chart, rotafolios o papelógrafo, es un caballete con un bloc de hojas de papel de tamaño DIN A1. Tiene la peculiaridad de que los gráficos, dibujos o esquemas que se quieren mostrar se pueden haber preparado de antemano; además, respecto a la pizarra tiene la ventaja de que estos esquemas se pueden conservar para ser reutilizados en cualquier momento de la sesión. No obstante, tiene la desventaja de que, por su tamaño, más reducido que el de la pizarra blanca o tradicional, queda limitada su visibilidad en audiencias superiores a las 30 personas.

- El vídeo: tiene la ventaja de ofrecer imágenes en movimiento y su posibilidad de acercarse a la realidad es casi ilimitada. Su utilización requiere una programación, preparación y coordinación muy cuidadosa para ser intercalado durante una sesión. Uno de sus inconvenientes es que la elaboración de este tipo de

TABLA 3. Tamaño y tipo de letra

$\begin{array}{ll}\text { Tipo de letra: sans serif } & \\ \text { Salas }>200 \text { asientos } & \text { Título: } 42 \text { puntos } \\ & \text { Texto principal: } 36 \text { puntos } \\ \text { Salas }<200 \text { asientos } & \text { Título: } 36 \text { puntos } \\ \text { Salas }<50 \text { asientos } & \text { Texto principal: } 28 \text { puntos } \\ & \text { Título: } 32 \text { puntos } \\ & \text { Texto principal: } 24 \text { puntos }\end{array}$

Fuente: Holzl J, 
material requiere muchas horas de trabajo y el disponer de unos recursos especiales, tanto materiales como humanos.

- Los objetos: la utilización de objetos para ser mostrados durante una exposición oral no es recomendable cuando se trata de una gran audiencia debido al efecto distractor que se puede producir al pasar el objeto. Su uso debe quedar reservado para pequeñas audiencias en las que la observación del objeto puede ser mucho más rápida.

- Las transparencias, las diapositivas y las presentaciones electrónicas, con toda seguridad, son los medios audiovisuales más utilizados durante una exposición. El diseño y recomendaciones para su elaboración es común para cada una de ellas:

- Contenido: es necesario seleccionar y simplificar la información que se quiere mostrar; se recomienda que el texto escrito no exceda de ocho líneas por seis palabras en cada línea ya que un exceso de información dificulta la lectura de la proyección. En caso de presentar una tabla, se debería limitar la información a cuatro columnas y a siete filas, como máximo.

- Tamaño y tipo de las letras: para presentaciones de diapositivas electrónicas (PowerPoint), $\mathrm{Holzl}^{7}$ recomienda usar un tipo de letra sans serif: Helvética 0 Arial ya que al ser "menos decorativas" que otros tipos son fáciles de leer. En cuanto al tamaño dependerá de la dimensión de la sala donde se vaya a realizar la exposición (tabla 3). Es preferible utilizar letras minúsculas ya que se leen más fácilmente que las mayúsculas.

- Color: el color se debe utilizar con una finalidad funcional más que decorativa; por tanto debe aplicarse de forma lógica, reservando algunos colores para los títulos o subtítulos, manteniendo una uniformidad durante toda la presentación y evitando su exceso ${ }^{7}$. También es importante considerar su significado cultural: rojo para las prohibiciones o limitaciones, verde y azul para resaltar aspectos positivos (saludables). Además, se deben evitar colores pálidos, por la dificultad en visualizarlos una vez proyectada la diapositiva. También se debe considerar el fondo de la proyección: si es oscuro será acertado utilizar colores claros, pero siempre teniendo en cuenta hacerlo de forma contrastada.

- En la actualidad es frecuente que con una presentación electrónica se incluya sonido o se incorpore un vídeo, aunque esta última opción se debería reservar para las presentaciones que tienen un objetivo básicamente educativo. Por otro lado, la inclusión de imágenes, animaciones, sonido o vídeo requieren un mayor espacio en el disco duro del ordenador, por lo que debemos asegurarnos de que el día de la presentación se dispondrá de un ordenador con capacidad suficiente para soportar los archivos de nuestra proyección, y que estarán instalados los players para visualizar la animación ${ }^{8}$.

\section{DESPUÉS DE LA EXPOSICIÓN ORAL}

Después de la presentación, es importante hacer una valoración de la sesión con el objetivo de identificar los aspectos que debemos mejorar en nuestras habilidades oratorias y que pueden redundar en exposiciones futuras.

También es de gran ayuda grabar en vídeo o casette la presentación para, después de visualizarlo u oirlo, hacer las propias críticas y rectificaciones. La grabación es un recurso accesible y sencillo que puede darnos una gran cantidad de información; su utilización es muy aconsejable tanto para personas que comienzan a realizar exposiciones orales, ya que les permite corregir y mejorar aspectos formales (dicción, entonación, gestos, expresiones, etc.), como para personas ya experimentadas, que desean mejorar y/o clarificar el mensaje que van a transmitir.

Otra opción es dar a un colega un checklist o «lista de evaluación " para que valore en directo la calidad de la presentación.

\section{BIBLIO,GRAFÍA}

1. Morgan N. The kinesthetic speaker. Putting action into words. Harv Bus Rev 2001;79:112-20.

2. Beitz JM. Dynamics of effective oral presentations. AORN J 1994;59 (5):1026-32.

3. Bados A. Hablar en público. Guía práctica para lograr habilidad y confianza. Madrid: Ediciones Pirámide, 1991.

4. Pease A. El llenguatge del cos. Barcelona: Paidós/Edicions 62, 1998.

5. Puchol L. Hablar en público. Madrid: Diaz de Santos, 1997.

6. Amat O, Pineda P. Aprendre a ensenyar. Bellaterra: Edicions Gestió 2000; 1996.

7. Holzl J. Twelve tips for effective PowerPoint presentation for the technologically challenged. Medical Teacher 1997;3:175-9.

8. Davis M. Scientific papers and presentations. San Diego: Academic Press, 1997. 